DOI 10.37882/2223-2982.2021.09.39

\title{
НАЦИОНАЛЬНО-КУЛЬТУРНАЯ ЛЕКСИКА КАК ОТРАЖЕНИЕ ЯЗЫКОВОЙ КАРТИНЫ МИРА ГОВОРЯЩИХ (НА ПРИМЕРЕ ТЕРРИТОРИАЛЬНОГО ДИАЛЕКТА ИСПАНСКОГО ЯЗЫКА МЕКСИКАНСКОГО ШТАТА КИНТАНА-РОО)
}

\begin{abstract}
NATIONAL AND CULTURAL VOCABULARY AS A REFLECTION OF THE LINGUISTIC PICTURE OF THE WORLD OF SPEAKERS (ON THE EXAMPLE OF THE TERRITORIAL DIALECT OF THE SPANISH LANGUAGE OF THE MEXICAN STATE OF QUINTANA ROO) V. Shakhnazaryan
\end{abstract}

Summary: The article is devoted to the study of national and cultural vocabulary, reflecting the linguistic picture of the world of the Spanishspeaking part of the population of the Mexican state of Quintana Roo, as well as bilinguals (Spanish - Maya). The purpose of the study is to identify the methods of education and the use of national-cultural vocabulary, as well as the factors that influenced the formation of ethnically marked lexical units, within the specifics of the mentality of the Spanish speakers in the studying region. The object of research is lexical units that have a national-cultural specificity of use. Among them: fixed expressions related to lively colloquial speech, borrowings from the English language, Spanish vocabulary proper (léxico patrimonial), ethnographic dialectisms. During the study, it was noted that the direct relationship with the mental activity of native speaker and user makes the language not just a means of communication, but also a way of broadcasting the worldview of the speaker with other communicators, reflecting the inner world in terms of the peculiarities of mentality, collective national worldview.

Keywords: vocabulary with national and cultural features, metaphors and idioms, language picture of the world, specific mentality, Mexican national variant of Spanish, Quintana Roo state.

\author{
Шахназарян Владимир Михайлович \\ Аспирант, Российский университет дружбы народов \\ (Москва) \\ vlad_shakhov@mail.ru
}

Аннотация: Статья посвящена исследованию национально-культурной лексики, отражающей языковую картину мира испаноговорящей части населения мексиканского штата Кинтана-Ро0, а также билингвов (испанский майя). Цель исследования заключается в выявлении приемов образования и употребления национально-культурной лексики, а также факторов, повлиявших на формирование этнически маркированных лексических единиц, в рамках специфики менталитета носителей испанского языка исследуемого региона. В качестве объекта исследования выступают лексические единицы, имеющие национально-культурную специфику употребления. Среди них: устойчивые выражения, относящиеся к живой разговорной речи, заимствования из английского языка, собственно испанская лексика (léxico patrimonial), этнографические диалектизмы. В ходе исследования было отмечено, что непосредственная взаимосвязь с мыслительной деятельностью его носителя и пользователя делает язык не просто средством построения коммуникации, но и способом трансляции мировоззрения говорящего с другими субъектам коммуникации, отражения внутреннего мира с точки зрения особенностей менталитета, коллективного национального мировосприятия.

Ключевые слова: национально-культурная лексика, метафоры и идиомы, языковая картина мира, специфика менталитета, экспрессивно-окрашенные слова, мексиканский национальный вариант испанского языка, штат Кинтана-Ро0.
Я зык как основная категория и предмет лингвистики, в первую очередь, является средством построения коммуникации и способом выражения мыслительной деятельности человека посредством системы фонетических, лексических и грамматических инструментов $[2 ; 5]$. При этом непосредственная взаимосвязь с мыслительной деятельностью его носителя и пользователя делает язык не просто средством построения коммуникации, но и способом трансляции мировоззрения говорящего с другими субъектам коммуникации, отражения внутреннего мира с точки зрения «особенностей менталитета, коллективного национального мировосприятия» [9, с. 124]. В соответствии с этим, цель работы заключается в выявлении приемов образования и употребления национально-культурной лексики на территории мексиканского штата Кинтана-Роо, а также факторов, повлиявших на формирование испаноязычных лексических единиц, в рамках специфики менталитета носителей испанского языка данного региона.

Актуальность настоящего исследования обусловлена недостаточной изученностью мексиканского национального варианта испанского языка как самого сложного с точки зрения романской диалектологии и вариантологии. Известный мексиканский лингвист X.M. Лопе Бланч, работая над Лингвистическим атласом Мексики, выделил на территории страны 17 диалектных зон. [11] Позже, в 1987 году, он определил всю терри- 
торию полуострова Юкатан (частью которого является штат Кинтана-Роо) как отдельную диалектную зону, подвергшуюся сильному влиянию субстрата языка майя. [12, с 23] Лингвистические исследования испанского языка на территории штата Кинтана-Роо в современной науке представлены фрагментарно. Также считаем необходимым отметить, что многие данные 80-х - 90-х годов уже устарели, так как под влиянием множества экстралингвистических факторов на протяжении последних 25 лет активно меняется этнокультурный состав носителей языка в регионе. По данным Национального Института статистики, географии и информатики с 2000 по 2009 на территорию штата переехали жить и работать 110000 человек, с 2010 по 2020 годы - 156000 человек [10].

В качестве объекта исследования выступают устойчивые выражения, заимствования из английского языка, собственно испанская лексика (léxico patrimonial), этнографические диалектизмы. Эмпирической базой исследования послужили записи информантов, сделанные в рамках научной стажировки в Институте Кинтана-Роо, с высоким уровнем образования (не ниже бакалавриата) резидентов штата в возрасте от 24 до 65 лет. Основными методами исследования послужили: метод интервью, анкетирование, метод опосредованного наблюдения за речевым поведением, метод непосредственного участия в беседе, сравнительный и аналитический методы. В рамках эксперимента, информантам задавались дополнительные вопросы с целью конкретизировать лексическое значение отобранных единиц, установить особенности их употребления в конкретных ситуациях.

Основной составляющей национально-культурной лексики языка, которая выражает базовый пласт спецификации и особенностей языковой картины мира, говорящих являются метафоры и идиомы, относящиеся живой разговорной речи. Нами отобраны наиболее характерные для территориального диалекта испанского языка мексиканского штата Кинтана-Роо, например:

1. «Ir a dar patatús»

Дословно данная единица переводится, как 'naдать в обморок'. Выражение употребляется в значении притворяться. Идиома употребляется, как реакция на обман (выдумку) в виде добродушной шутки. Отметим также, что лексическая единица patatús, заимствованная из языка майя, утратила свое исконное значение 'поле', 'равнина' [14]:

- Es que me siento un poco fatal ('Чувствую себя неважно');

- No me digas que le vas a dar papatús ('Только не говори, что ты сейчас упадешь в обморок'). [Запись информантов]

Представленная идиома имеет коннотацию иронии, формирует дружескую, неформальную коммуникацию между говорящими.

2. «Ser chechón» Выражение переводится как 'быть плаксивым. В живой разговорной речи данное выражение употребляется с оттенком значения умиления или упрека. Аналогом данной идиомы в русском языке является фрраза «крокодиловы слезы». В мексиканском и пиренейском стандартах употребляется общеиспанский вариант: ser llorón. Обратимся к примеру:

- ¡No seas chechona, Gabriela! Te dije que no. ('He будь плаксой, Габриэла! Я сказала тебе - нет! ). [Запись информантов]

3. «lo busco y no lo busco»

Дословный перевод 'я ищу это и не ищу', однако глагол buscar 'искать' в испанском языке мексиканского штата Кинтана-Роо подвергся расширению лексического значения и также понимается как 'находить'. Таким образом, буквальный перевод данной конструкции: 'я ищу, но не нахожу этого'. Представленная идиоматическая конструкция имеет нейтральный эмоциональный окрас, однако точно указывает на этническую принадлежность говорящего - территорию полуострова Юкатан в Мексике. В общении с приезжими используется стандартная речевая формула, не относящаяся к категории идиоматических единиц: lo busco y no lo encuentro.

4. «Dar tirixtá»

Буквальный перевод идиомы, которая также образована из общеиспанского глагола и маизма, 'пожалеть о чем-либо'; аналогом идиомы в русском языке является фраза "Лучше сделать и пожалеть, чем не сделать и пожалеть», что означает 'обязательно пробовать, попытаться'. Обратимся к примеру:

- Yo en tu lugar lo intentaría. Es mejor probarlo o te va a dar tirixtá ('Я бы на твоем месте попытался. Лучше попробовать или можешь потом пожалеть'). [Запись информантов]

Приведенная в данном примере лексическая конструкция имеет негативный эмоциональный окрас, применяется как возможное следствие текущей нерешительности.

5. «Estar chiflando en la loma», которая буквально переводится как 'быть без денег'. С точки зрения идиоматического перевода данная фраза означает 'быть на мели', 'быть без гроша за душой'. Приведенное выражение используется для описания ситуаций, когда человек находится в сложной экономической ситуации. Общеиспанским аналогом данной идиомы является выражение - «quedarse $\sin d u r o »$, что в буквальном переводе означает 'остаться без копейки'.

Рассмотрим примеры:

- Sara no va con nosotros, está chiflando la loma ('Capa не едет с нами, она на мели') [Запись информантов];

- ¡En esa situación todos estamos chiflando la loma, 
nadie lo va a comprar! ('Мы все находимся в такой ситуации (без гроша), что никто не купит это'). [Запись информантов]

Данная идиома имеет негативный вектор с точки зрения эмоционального окраса и используется в ситуациях, в которых говорящий пытается эвфемизировать сложное положение и не делать на этом акцент.

В ходе исследования мексиканских идиом были проанализированы наиболее распространённые и часто употребляемые единицы. Исходя из представленных примеров, а также прочих единиц, проанализированных с целью исследования языковой картины мира носителей испанского языка мексиканского штата Кинтана-Роо, можно утверждать, что большинство единиц имеют позитивный характер. Они характеризуются либо положительным окрасом, либо приобретают шутливую форму, выражая практический подход к различным жизненным ситуациям и нацеленность на то, что любой вопрос можно решить. Это говорит о том, что испаноговорящая часть населения открыто относится к окружающему миру, не боится выражать эмоции.

Кроме идиом испанского происхождения в национально-культурной разговорной речи испаноговорящей части населения существует множество заимствованных жаргонных выражений, «основным источником которых является английский язык» [7, с. 67]. Данный пласт испанской лексики сформировался под влиянием социальных и культурных факторов, основными из которых являются приобретение английским языком в 40-х годах прошлого столетия статуса международного, глобализация, популяризация английского и американского уклада жизни, культуры и традиций среди молодых испаноговорящих людей, а также «соседствующее» расположение обеих стран [3]. Множественные заимствования в испанском языке англицизмов, демонстрируют превалирование в жизни их носителей принципов, подходов и привычек западного образца, которые выражаются в свободолюбии, гуманизме, постановке человеческой жизни, как наивысшей ценности, демократии. Все приведенные ниже примеры прошли путь «грамматической адаптации» и не воспринимаются носителями как инородные элементы, а также отражены в академических толковых словарях испанского языка Мексики:

1. celebrities (ucn.) / celebrities (англ.) - 'знаменитости' [16, p. 144]

Например: Castle, no estamos hablando sobre paparazzi y celebrities ('Касл, мы не говорим о папарацци и знаменитостях');

2. estrellas (ucn.) - estrellas (англ.) - 'звезды' [16, р. 169] Например: Todas las estrellas se mueven constantemente ('Все звезды постоянно движутся по отношению друг к другу');

3. chequear (ucn.) - check (анг.) -'проверить' [16, p. 147] Например: Sólo quería chequear que Andrew estaba bien ('Я просто хотела проверить, что с Эндрю все в порядке');

4. mixto (ucn.) - mix (англ.) - 'смешанный' [16, р. 597] Например: En los acuerdos sobre el ozono se ha aplicado un criterio mixto ('В соглашениях по озоновому слою используется смешанный подход');

5. cliquear (ucn.) - to click (англ.) -'печатать' [16, p. 151] Например: Los mayores de 40 años aprenden a cliquear ('Люди в возрасте 40 лет учатся печатать').

Еще одной характерной особенностью испанского языка в целом и территориального диалекта штата Кинтана-Роо, является наличие в живой разговорной речи большого количества слов-заместителей, которые с точки зрения смысловой нагрузки представляют собой «опустошенные / полуопустошенные лексемы» (такие слова легко взаимозаменяемы) [1, с. 178]. Данный лексический блок лингвисты разделяют на:

1. Опустошенные слова, с точки зрения смыслового значения:

- la educación de los niños es una cosa difícil (cosa = tarea) ('образование детей - трудная вещь (вещь = задача)');

- una sola cosa ocupa su mente (cosa = idea) ('одна вещь занимает его разум (вещь = идея)');

- expone las cosas como han pasado (cosas =hechos) ('oн разоблачает вещи, как они произошли (вещи = факты) '). [Запись информантов]

Как отмечает Э. Уэрта, в разговорном испанском языке наблюдается чрезмерное употребление опустошенных слов, что определенным образом характеризует национально-культурную особенность испаноговорящего населения [3, с. 253]. Множественное использование опустошённых слов свидетельствует о попытке упрощения процесса коммуникации, упрощении процесса поиска синонимичных конструкций для облегчения коммуникации. Носители испанского языка не задумываются о выборе синонимичных конструкций, более подходящих в том или ином контексте, а зачастую используют понятные всем конструкции «cosa» $u$ «cosas» [4]. Во главе угла стоит понимание друг друга в процессе коммуникации, а не намерение витиевато и красноречиво изложить свою мысль, хотя и в этом, испанцы не уступают другим языковым группам. Аналогичная ситуация наблюдается и в отношение прономинаций.

2. Прономинализации, которые определяются трансформацией лексем в местоимения из других частей речи в связи с потерей изначальной лексемой семантической характеристики или явным снижением значимости его семантики. В результате этого прономинализации используются для сохранения указывающей функции на исходный предмет, объект или субъект, о котором идёт речь, при этом минимизации количества изначально используемой лексемы [2, с. 226]. Например:

- Mi madre dijo lo mismo que no volvería a parir ('Моя 
мама сказала тоже самое, что она больше не будет рожать');

- Llamamos a Eva, pero nunca respondió ('Мы звонили $E в е$, но она так и не ответила').

3. Провербы, которые дословно переводятся как'небольшая пьеса, основанная на пословицах'. Лексемы, относящиеся к провебам, подразумевают неоднозначность трактовки без контекстуального применения. Каждая лексема, относящаяся к провебам, имеет в среднем от 15 и более значений без учета устойчивых выражений, в состав которых они входят [2, с. 228]. Например:

1. hacer может использоваться в таких значениях, как 'делать', 'участвовать', 'заниматься', 'вести', 'заставить', 'помочь' и др. [10]

- Sólo siento que debo hacer algo ('Просто у меня такое чувство, будто я должна сделать хоть что-то'); - Lo único que quería hacer era música ('Знаете, все, чем я хотел всегда заниматься - это писать музыку') [Запись информантов];

2. poner может использоваться в таких значениях, как 'положить', 'поставить', 'создать', 'обеспечить', 'сделать,' 'привести' и др. [10]

- Tampoco debe poner en peligro la capacidad para desempeñar sus funciones y poderes ('В равной степени оно не должно ставить под угрозу способность Совета осуществлять свои функции и полномочия');

- También deben intentar determinar cuándo salir y poner su dinero en otro sitio ('Они должны также попытаться определить, когда следует забрать деньги и вложить их в другом месте') [Запись информантов];

3. tener может использоваться в таких значениях, как 'иметь', 'получить', 'оказать', 'принять', 'завести','привести' и др. [10]

- Pero me gustaría tener una alternative ('Но я хотел бы иметь еще один вариант, на столе');

- Podrían tener un albergue infantil como fachada ('Они могли устроить учреждение по уходу за детьми на дому в качестве прикрытия'). [Запись информантов]

Как отмечает С.А. Яковлева лексический состав испанского языка настолько разнообразен, что одно и то же слово может обозначать разные понятия или вещи в зависимости от места и контекста употребления. [8, c. 16] Наличие в языке множества универсальных слов, которые можно употребить в самых разнообразных ситуациях, в контексте каждой из которых они будут иметь разные значения, также является способом упрощения языка и коммуникации в целом. В рамках изучения языка, обучаемому необходимо запомнить меньшее количество лексем. Как и в предыдущих случаях, такой подход свидетельствует о любви к свободе, стремлению снять любые ограничения, занимающие разум и отвле- кающие от более важных жизненных вопросов, самой жизни в целом.

4. Экспрессивно-окрашенные слова. Например, слово «porquería», означающее 'грязь', 'дрянь', 'отстой', 'чушь', 'бред', 'гадость'. [16] В данном случае наблюдается ярко выраженный экспрессивный окрас во многих значениях слова, которое, чаще всего, используется для выражения эмоционального состояния человека, отношения человека к чему-то или кому-то:

- Mucho mejor que esa porquería de Río ('Это куда лучше, чем та дрянь в Рио');

- No te molestes, es una porquería ('Не стоит, приятель, это отстой'). [Запись информантов]

Испанская речь очень богата экспрессивно-окрашенными словами и выражениями в виду того, что испанцы относятся к одному из самых эмоциональных народов с точки зрения менталитета. Испанцы эмоционально выражают свои мысли, с жестикуляциями дискутируют на ту или иную тему, говорят о своих эмоциях, не стесняются перебивать друг друга в процессе беседы и это считается нормой [7]. Поэтому в лексиконе испаноговорящего населения присутствует много разнообразных экспрессивно-окрашенных слов и выражений.

В качестве огромного пласта национально-культурной лексики всех вариантов испанского языка ученые выделяют этнографизмы, или этнографические диалектизмы, к которым можно отнести и кулинарную лексику, как один из способов выражения языковой картины мира. У испаноговорящих кулинария занимает особое место, они акцентируют внимание на вкусах и запахах, как способе мировосприятия и мироощущения, ещё одного способа получения удовольствия от жизни [6, с. 88]. При этом основу данного пласта составляют топонимы, которые представляют собой результат историко-географического формирования национальной культуры и кулинарии как её части:

- Camarones pibil a la quintanarroense ('Креветки, запечённые под землей по-кинтанаросски');

- Marquesita chetumaña ('Вафля по-четумальски');

- Puerco yucateco ('Свинина по-юкатански').

Таким образом, национально-культурная лексика испанского языка на территории мексиканского штата Кинтана-Роо отличается обилием употребления в речи маизмов, которые изменили свое исконное значение, множественными приёмами упрощения, введения в язык слов, которые можно использовать в большом количестве вариативных значений в зависимости от контекста, лексем, которые легко взаимозаменяемы. Для испанского языка также характерен ярко выраженный экспрессивно-эмоциональный окрас. Часто встречаются топонимы, в особенности в кулинарном тезаурусе, а также заимствования из английского языка. 


\section{ЛИТЕРАТУРА}

1. Ахренов, А.В. 0 некоторых направлениях в изучении языковой картины в полинациональных языках (на прим. испанского)// Новое в переводоведении и лингвистике: матер. междунар. науч.-практ. конф. - Орехово-Зуево: Гос. гуманит.-технол. ун-т, 2012. - С. 175-182.

2. Бахронова, Д.К. Метафоры в языковой картине мира (на материалах английского и испанского языков)// Молодой ученый. - 2020. - № 1(291). - С. 225-228.

3. Долженкова, В.В. Некоторые характерные особенности испанской разговорной лексики в контексте национальной языковой картины мира// Litera. 2019. - № 6. - С. 250-256.

4. Журавлева, Н.Ю. Словообразовательный и лексико-семантический потенциал оттопонимических номинаций в мексиканском национальном варианте испанского языка: автореф. дисс. ... канд. филолог. наук: 10.02.05. - Москва: Рос. ун-т дружбы народов (РУДН), 2013. - 20 с.

5. Иовенко, В.А. Национальное мировоззрение в двуязычной коммуникации// Филология. - 2013. - № 4(31). - С. 303-311.

6. Смирнова, Е.В. Топонимические культурные доминанты в гастрономическом тезарусе испанцев// Русистика. - 2015. - № 1. - С. 87-91.

7. Пронченко, Е.Н. Топонимическая система языковой картины мира испанского языка// Университетские чтения - 2008: матер. науч.-методич. чтений. Пятигорск: Пятиг. гос. лингв. ун-т, 2008. - С. 64-69.

8. Яковлева, С.А. Испанский язык как полинациональный: геолингвистический и лексико-семантический анализ языка испаноамерики (на примере мексиканизмов). Автореф. дис. ... д. филол. н. Москва: МГОУ, 2016. 48 с.

9. Яковлева, Т.В. Этнокультуроведческая лексика как отражение языковой картины мира// Инновации в науке: матер. XVI междунар. заочной науч.-практ. конф. - Ч. ІІ. (28 января 2013 г.). - Новосибирск: Изд. «СибАК», 2013. - С. 121-127.

10. Instituto Nacional de Estadística, Geografía e Informática (INEGI). II Censo de población y vivienda. [Электронный ресурc]. http://cuentame.inegi.gob.mx/ poblacion/migracion.aspx?tema $=P$

11. Lope Blanch, J.M. Atlas lingüístico de México. - México: El Colegio de México, 1994. 400 p.

12. Lope Blanch, J.M. Estudios sobre el español de Yucatán. - México: UNAM, 1987. 198 p.

13. Diccionario Real Academia Española. [Электронный ресурс]. https://dle.rae.es/

14. Gómez Navarrete, J.A. Diccionario introductorio Español - Maya, Maya - Español. - Chetumal: UQR00, 2009. 198 p.

15. Diccionario de mexicanismos / Academia Mexicana de la Lengua; dir. Company Company. - México: Siglo XXI, 2010. 648 p.

16. Lara Ramos, L.F. (coord.). Diccionario del Español de México. - México: El Colegio de México, 2010. - 1706 p. 